\title{
CARCINOMA OF THE PANCREAS AND EXTRAHEPATIC BILE DUCTS*
}

\author{
Henry K. Ransom, m.d. \\ Associate Professor of Surgery, University of Michigan School of Medicine
}

ANN ARBOR, MICHIGAN

\section{INTRODUCIION}

$\mathrm{I}^{\mathrm{N}}$ $\mathrm{N}$ spite of the many refinements in diagnostic methods and the great variety of new laboratory procedures which have been developed during the past few decades, the differential diagnosis of obstructive jaundice remains nearly as difficult as it was some fifty years ago when Courvoisier ${ }^{1}$ first formulated his now famous law. This law, well known to students of medicine, is concerned with the differentiation between those obstructions of the common duct due to stones and "obstructions of other kinds." Literally translated, it is as follows: "With obstruction of the common duct by stone, dilatation of the gall-bladder is rare; the organ is usually shrunken. With obstruction of other kinds, on the contrary, distention is the rule; shrinking occurs in only one-twelfth of these cases."

For all practical purposes, "the obstructions of other kinds" referred to by Courvoisier are the cancerous obstructions due either to a primary or secondary nodule so situated that it is capable of occluding or compressing the ductus choledochus. Such obstructions caused by malignant disease are usually found in the lower portion of the duct and are ordinarily considered as being due to a primary carcinoma of the head of the pancreas. Concerning cancer in this location, Graham $^{2}$ has pointed out that "within an area having a radius of not more than $0.5 \mathrm{~cm}$., a carcinoma may arise in any one of the following structures: (I) the ampulla of Vater; (2) the end of the common bile duct; (3) the end of the duct of Wirsung;
(4) the glandular tissue at the head of the pancreas; and ( 5 ) the duodenal mucous membrane covering the biliary papilla." In $19 \mathrm{I}_{4}, \mathrm{Crohn}^{3}$ also called attention to this fact and contended that the site of the neoplasm could usually be determined by careful examination of the duodenal contents. Moreover, the presence of carcinoma in the pancreas is not necessarily confined to the head of the gland, but as is indicated by numerous recorded instances, the neoplasm may arise from the body or tail of the organ. In such cases, jaundice may either be absent throughout the entire course of the disease, or else appear only during the late stages.

In view of the advanced stage of the disease and the hopeless condition of most of the patients applying for surgical aid, the precise point of origin of such a carcinoma may appear to be largely a matter of academic interest. However, reports of successful resections of the lower end of the common duct for cancer, usually performed by means of a transduodenal approach, have appeared fairly frequently in the recent surgical literature (Potter, ${ }^{4}$ Judd, ${ }^{5}$ Walters, ${ }^{6}$ Hunt $^{7}$ ). Having in mind the more elaborate surgical procedures for dealing with these lesions, such as the one proposed by Whipple, Parsons and Mullins, ${ }^{8}$ and the newer methods for resection of the tail of the pancreas as suggested by Clute, ${ }^{9}$ and by Rives, Romano and Sandifer, ${ }^{10}$ the subject perhaps merits a renewed interest.

For these reasons the present study was undertaken. An attempt was made first, to determine the relative incidence of carcinoma in these various adjoining structures and, second, to clarify if possible

* From the Department of Surgery, University of Michigan. 
the early clinical picture in order to facilitate diagnosis at a time when more patients might be candidates for radical surgery. Accordingly, the records of all cases of carcinoma of the pancreas and extrahepatic bile ducts, observed in the University Hospital from July 1,1925 to July I, 1937, were assembled for review. During this twelve year period, a final diagnosis of carcinoma of the pancreas or extrahepatic bile ducts was recorded in I 58 instances. During this same period there were 246,986 patients admitted to the medical and surgical wards of the hospital. This last frgure indicates only new admissions and does not include re-entries or return visits. Thus the incidence of carcinoma of the pancreas and major bile ducts among hospital patients was one in 1,563 . It will be noted from Table $\mathrm{I}$ that in

TABLE I

DIAGNOSIS IN 158 CASES

\begin{tabular}{|c|c|c|}
\hline Method of Diagnosis & $\begin{array}{l}\text { No. of } \\
\text { Cases }\end{array}$ & $\begin{array}{c}\text { Per } \\
\text { Cent }\end{array}$ \\
\hline 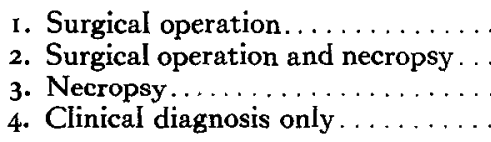 & $\begin{array}{l}79 \\
\text { I0 } \\
20 \\
49\end{array}$ & $\begin{array}{r}50.0 \\
6.33 \\
\mathrm{I} 2.66 \\
31.01\end{array}$ \\
\hline Total. & I 58 & I 00.0 \\
\hline
\end{tabular}

forty-nine of these cases, the diagnosis was based upon clinical data only. Because of the possibility of mistaken diagnoses in this group, it was believed that the study would be of greater value if only those cases in which the diagnosis was verified by operation or necropsy, were utilized for the statistical survey. Accordingly the detailed study was limited to the remaining I 09 case records. It will be noted that there were seventy-nine operative diagnoses and thirty necropsy diagnoses.

Table II gives the anatomic location of the primary lesion as it was determined by the operating surgeon or prosector. According to these observations, the Iesion involved the head of the pancreas, either alone or as part of a more extensive process, in nearly 60 per cent of the cases, while the body of the gland, alone or along with the head or tail or both, was affected in 30 per cent of the group. Carcinoma of the common duct, including the ampulla of Vater, was found in approximately 17 per cent. Thus from these data which were obtained chiefly at the operating table, the head of the pancreas was found to be

TABLE II

LOCATION OF PRIMARY LESION IN 109 VERIFIED CASES

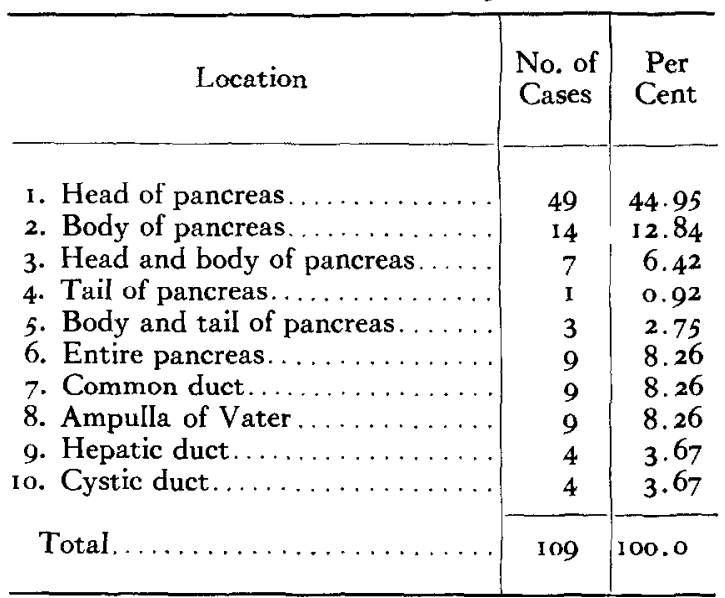

affected more frequently than any other single region, while a primary carcinoma of one of the major bile ducts was noted in about one-fourth of the cases. As will be emphasized later, at the time of operation it is frequently impossible to determine by palpation alone the exact site of the primary lesion. This is especially true in the advanced cases when contiguous structures have been involved, and in such cases the exact point of origin can only be told with certainty by post-mortem examination with histological study of the tissues.

\section{AGE AND SEX INCIDENCE}

Table III shows the distribution of the Iog cases according to sex and age. The ratio of men to women was approximately two to one. These findings are in accord with those of other observers (Mirallie, ${ }^{11}$ DaCosta, ${ }^{12}$ Speed, ${ }^{13}$ Futcher, ${ }^{14}$ Ancelot, ${ }^{15}$ Leven, ${ }^{16}$ and Friedenwald and Cullen ${ }^{17}$ ). Rienhoff and Lewis ${ }^{18}$ found a somewhat 
higher incidence among males $(3: 1)$ as did Rives, Romano and Sandifer $(4 \cdot 3: I)$, while in Kiefer's ${ }^{19}$ series of thirty-three cases, there were 18 males and fifteen females.

TABLE III

AGE AND SEX INCIDENCE

\begin{tabular}{|c|c|c|}
\hline Sex & $\begin{array}{l}\text { No. of } \\
\text { Cases }\end{array}$ & $\begin{array}{l}\text { Per } \\
\text { Cent }\end{array}$ \\
\hline \multicolumn{3}{|l|}{ Sex Incidence } \\
\hline $\begin{array}{l}\text { Males. . } \ldots \ldots \ldots \ldots \ldots \ldots \ldots \ldots \ldots \\
\text { Females. } \ldots \ldots \ldots \ldots \ldots \ldots \ldots\end{array}$ & $\begin{array}{l}75 \\
34\end{array}$ & $\begin{array}{l}68.8 \mathrm{I} \\
3 \mathrm{I} . \mathrm{I} 9\end{array}$ \\
\hline TotaI..... & 109 & 100.0 \\
\hline
\end{tabular}

\begin{tabular}{c|c|c}
\hline \multicolumn{2}{c}{ Distribution of Cases According to Age } \\
\hline Age & No. of Cases & Per Cent \\
\hline & & \\
\hline $20-29$ & $\mathrm{I}$ & $.9 \mathrm{I}$ \\
$30-39$ & 5 & 4.59 \\
$40-49$ & $\mathrm{I} 6$ & 14.68 \\
$50-59$ & 42 & 38.54 \\
$60-69$ & 34 & $3 \mathrm{I} .20$ \\
$70-79$ & I0 & 9.17 \\
$80-89$ & $\mathrm{I}$ & .91 \\
\hline
\end{tabular}

The youngest patient was 29 years old and the oldest 82 years; the average age was 56.9 years.

With regard to the age distribution, it will be noted that nearly 85 per cent of the patients were in the so-called cancer age, i.e., between 40 and 70 , and that the disease was quite uncommon in patients under 40. The average age for the group was 56.9 years.

\section{CLINICAL MANIFESTATIONS}

\section{HISTORY}

Weight Loss. Loss of weight was the symptom common to the largest number of patients; it was absent in only frve of the ninety-frve cases in which the records were complete on this score. Definite mention of weight loss was therefore found in 94.74 per cent. The weight loss was usually rapid and frequently considerable, as is shown in Table IV, where it is seen that the amount in nearly one-seventh of the cases exceeded 40 pounds ( $18.2 \mathrm{~kg}$.) and in the one case in which the greatest loss was recorded,

TABLE IV WEIGHT LOSS IN 95 CASES

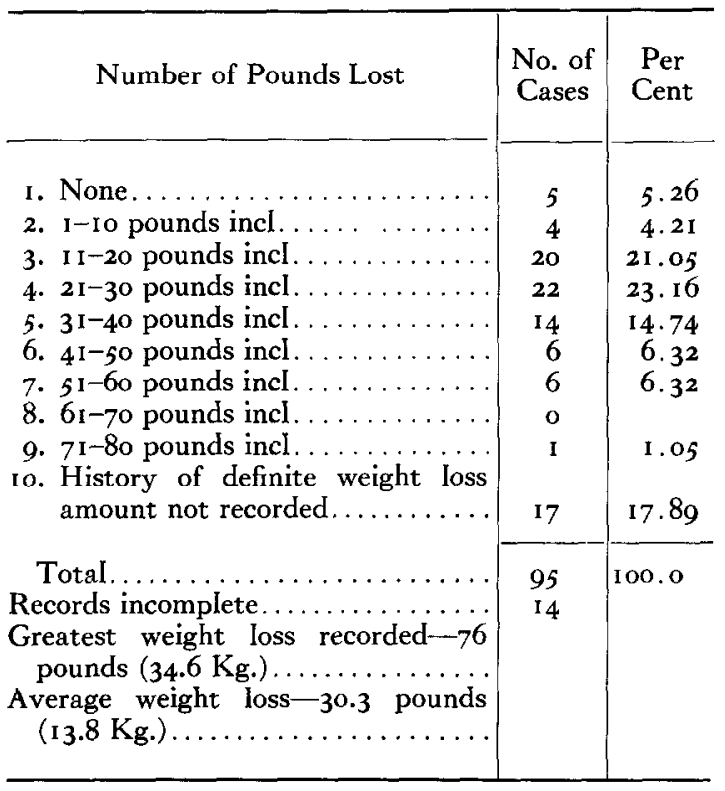

amounted to 76 pounds $(34.6 \mathrm{~kg}$.). The average amount of weight lost in the seventy-three cases in which definite figures were available was 30.3 pounds $(13.8 \mathrm{~kg}$.). These figures are approximately the same as those reported by other observers. Thus Kiefer found the average weight loss in his series to be 28 pounds, Levin 32 pounds, Hick and Mortimer ${ }^{20} 37$ pounds, Futcher 32 pounds, Eusterman ${ }^{21} 29$ pounds and Mussey $^{22} 26$ pounds. Considering the fact that the average duration of symptoms was 5.5 months, the average weight loss per month amounted to 5.5 pounds (2.5 kg.). This is practically the same as Kiefer found in his Brigham Hospital series. Since loss of weight is such a general symptom and one found in such a variety of chronic conditions, particularly malignant disease, its presence is not of great diagnostic import. The most significant feature of weight loss in pancreatic cancer is the extreme degree of the emaciation and the rapidity of its development.

Jaundice. Table $\mathrm{v}$ indicates the relative frequency of the other symptoms com- 
monly ascribed to carcinoma of the pancreas. It will be noted that with the exception of weight loss, jaundice occurred

Table $v$

FREQUENCY OF COMMON SYMPTOMS

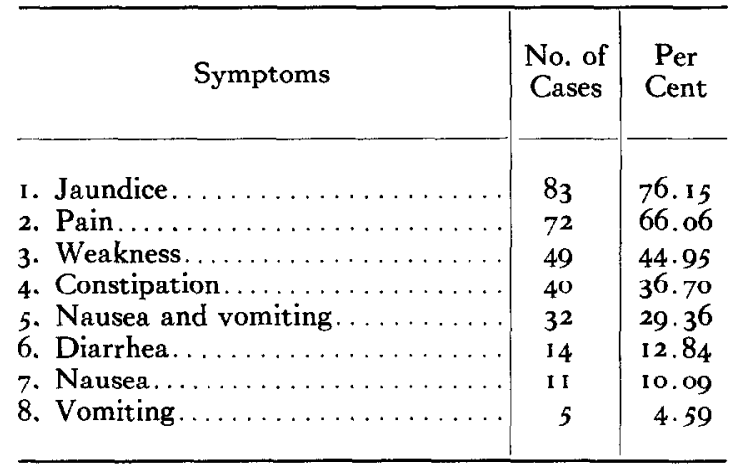

with greater frequency in the history than any of the other symptoms, it being a definite complaint in eighty-three cases, or 76.15 per cent of the group. Jaundice alone was the chief complaint and the one for which medical advice was sought in thirty-nine cases, or 35.78 per cent (Table $\mathrm{vI})$. If to this are added those cases in

TABLE VI

CHIEF COMPLAINTS

\begin{tabular}{|c|c|c|}
\hline Complaint & $\begin{array}{c}\text { No. of } \\
\text { Cases }\end{array}$ & $\begin{array}{l}\text { Per } \\
\text { Cent }\end{array}$ \\
\hline 1. Jaundice. & 39 & $35 \cdot 78$ \\
\hline 2. Abdominal pain.... & 30 & $27 \cdot 52$ \\
\hline 3. Jaundice and abdominal pain. & 15 & 13.76 \\
\hline 4. Jaundice and weakness....... & 9 & 8.26 \\
\hline 5. Weakness and weight Ioss. . & 6 & $5 \cdot 50$ \\
\hline 6. Abdominal pain and tumor. & 2 & 1.83 \\
\hline 7. Weakness and abdominal pain... & 2 & I. 83 \\
\hline $\begin{array}{l}\text { 8. Abdominal pain, tumor and jaun- } \\
\text { dice. } \ldots \ldots \ldots \ldots \ldots \ldots \ldots \ldots\end{array}$ & I & .92 \\
\hline 9. Abdominal tumor $\ldots \ldots \ldots$ & $\mathbf{I}$ & .92 \\
\hline 10. Pruritus............. & $\mathbf{I}$ & .92 \\
\hline II. Nausea and vomiting... & I & .92 \\
\hline 12. Increasing constipation... & I & .92 \\
\hline 13. Ascites............. & $\mathbf{I}$ & .92 \\
\hline Total. & IO9 & 100.0 \\
\hline
\end{tabular}

which jaundice occurred as the chief complaint in combination with other symptoms, the total is sixty-four cases, or 58.72 per cent, and in combination with abdominal pain was the initial complaint in two additional cases. Pruritus was men- tioned in thirty-seven, or 44.6 per cent of the jaundiced cases and occurred once as the chief complaint and once as the initial symptom.

Pain. Contrary to the usual statement that the clinical picture of carcinoma of the pancreas is one of progressive painless jaundice, pain was a prominent symptom in this series, as it occurred in two-thirds of the cases. In the non-icteric patients, notably those with lesions in the body or tail of the pancreas, it was almost always the chief complaint as well as the initial symptom. It was a major symptom in all such cases. A separate report of these cases has been made previously by the author. ${ }^{23}$

In the group of cases now under consideration, abdominal pain alone was the chief complaint in thirty cases, or 27.52 per cent, while pain in conjunction with jaundice, tumor mass or weakness, was the chief complaint in twenty more cases, or I 8.34 per cent. Thus it appeared in the chief complaints in fifty cases, or 45.86 per cent of the group. As shown in Table vil,

\begin{tabular}{|c|c|c|}
\hline \multicolumn{3}{|l|}{$\begin{array}{c}\text { TABLE VII } \\
\text { INITIAL SYMPTOMS }\end{array}$} \\
\hline Symptom & $\begin{array}{l}\text { No. of } \\
\text { Cases }\end{array}$ & $\begin{array}{c}\text { Per } \\
\text { Cent }\end{array}$ \\
\hline 1. Abdominal pain. & 51 & 46.80 \\
\hline 2. Jaundice....... & 27 & 24.77 \\
\hline 3. Weakness........ & 14 & 12.84 \\
\hline 4. Nausea and vomiting. ......... & 7 & 6.42 \\
\hline 5. Diarrhea................. & 3 & 2.75 \\
\hline 6. Jaundice and abdominal pain.... & 2 & I. 83 \\
\hline 7. Increasing constipation ......... & 2 & 1.83 \\
\hline 8. Pruritus............ & I & .92 \\
\hline 9. Abdominal tumor....... & I & .92 \\
\hline 10. Ascites and pain........ & $\mathbf{I}$ & .92 \\
\hline Total. & 109 & 100.0 \\
\hline
\end{tabular}

abdominal pain alone was the most common initial symptom, being the first evidence of departure from normal health to be noted by the patient in nearly one-half of the cases. The frequent occurrence of abdominal pain in pancreatic carcinoma has been emphasized by other writers. Thus Rienhoff and Lewis in their 
review of the Johns Hopkins Hospital cases reported it in 87.16 per cent; Rives, Romano and Sandifer in 77.4 per cent; Kiefer in 63.6 per cent; Frjedenwald and Cullen in 83 per cent; Futcher in 58 per cent; Mussey in 88 per cent; and Levin in all of the cases studied.

Elaborate descriptions are to be found concerning the character or type of pain in pancreatic cancer. In general they may be summarized as follows: (I) a boring or burning steady pain located in the midepigastrium and sometimes radiating into the back; (2) a colicky pain in the right upper quadrant, possibly with radiation to the right shoulder, and quite capable of simulating gallstone colic; and (3) a paroxysmal type of pain beginning at or near the umbilicus.

Such pain may be influenced by various factors. Thus relief is sometimes obtained by change in position, such as leaning forward, lying in the prone position, by the ingestion of food or soda, by vomiting, or by defecation.

Various explanations have been offered to account for the pain. Among these are obstruction to the pancreatic or bile ducts, thus producing stasis of pancreatic secretion or bile, mechanical pressure on the celiac plexus, and direct infiltration of the pancreas associated with hemorrhage and pancreatitis. Leven reports one case in which post-mortem examination of the tissues in the region of the celiac plexus showed infiltration of the sympathetic nerve trunks by tumor tissue, resulting in marked compression of these nerves. The lower half of the celiac plexus is closely associated with the posterior surface of the body of the pancreas and many nerve fibers leaving the plexus perforate the substance of the pancreas. Considering the fact that pain is especially severe in carcinoma of the body of the gland, and that the lesion is usually well advanced before symptoms appear, mechanical pressure or direct infiltration of nerve sheaths or of the nerve trunks themsclves seems to be a plausible explanation.
In Tables vili and Ix an attempt has been made to tabulate the location and character of the pain in the seventy-two

\begin{tabular}{|c|c|c|}
\hline $\begin{array}{c}\text { TABLE VIII } \\
\text { LOCATION OF PAIN IN } 72\end{array}$ & CASES & \\
\hline Location & $\begin{array}{l}\text { No. of } \\
\text { Cases }\end{array}$ & $\begin{array}{c}\text { Per } \\
\text { Cent }\end{array}$ \\
\hline I. Right upper quadrant. . & 2 I & 20.17 \\
\hline 2. Mid epigastrium........ & 19 & 26.39 \\
\hline 3. Generalized over abdomen. . & 7 & 9.72 \\
\hline 4. Lower abdomen.... . . . . . . & 6 & 8.33 \\
\hline 5. Entire upper abdomen........ & 5 & 6.94 \\
\hline 6. Right upper quadrant and back. & 5 & 6.94 \\
\hline 7. Epigastrium and back. . . . . . & 4 & 5.56 \\
\hline 8. At umbilicus $\ldots \ldots \ldots \ldots \ldots \ldots$ & 3 & 4.17 \\
\hline 9. Left upper quadrant . . . . . . . . & 1 & 1.39 \\
\hline o. Low back.................. & $\mathbf{I}$ & 1.39 \\
\hline Total. & 72 & 100.0 \\
\hline
\end{tabular}

TABLE IX

TYPE OF PAIN IN 72 CASES

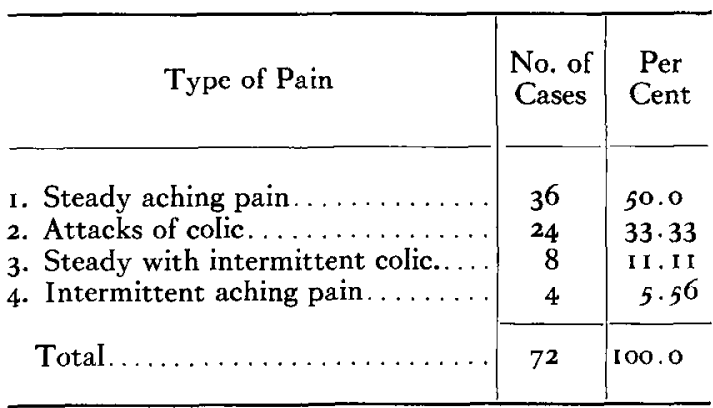

cases in which it was present. While the location was far from constant, the right upper quadrant and the mid-epigastrium were the regions most frequently mentioned. A steady aching pain occurred in one-half of the patients complaining of pain. The most striking characteristic was the unusual severity of the pain, especially in the non-jaundiced cases, obviously much worse than the pain of peptic ulcer, gastric carcinoma or cholecystitis. In one-third of the cases, the pain occurred in attacks of colic and being often located in the right upper quadrant, as weII as frequently being accompanied by jaundice, it occasionally resulted in an incorrect diagnosis of cholelithiasis or common duct stones. In eight 
cases, there was the steady type of pain, with superimposed attacks of colic, while in four cases the pain, while not of the colicky type, was nevertheless intermittent in character.

Weakness. From Table $\mathrm{v}$ it will be noted that next to jaundice and pain, a complaint of loss of strength occurred most often. Marked weight loss is usually accompanied by loss of strength, and therefore in all probability weakness occurred in the majority of the patients. However, in 45 per cent of the group, the asthenia was so marked that it constituted an important complaint.

Constipation and Diarrbea. In over onethird of the cases constipation was a definite symptom, while diarrhea was specifically mentioned in one-eighth. While constipation is of such common occurrence in patients of this age group that its presence may not be of great diagnostic significance and might be regarded as purely incidental, nevertheless a reading of these case histories convinces one that there was frequently an exaggeration of previous chronic constipation. Even though it had not previously been troublesome, when it developed during the course of the disease it was particularly marked. This latter finding is of considerable practical interest, especially in the non-jaundiced patients, inasmuch as severe constipation, when found in a patient of middle age, associated with weight loss, abdominal pain, the presence of occult blood in the stools and indeterminate findings on roentgenologic examination of the colon, may lead to a mistaken diagnosis of carcinoma of the colon.

From the standpoint of diagnosis, diarrhea was less significant. While in the presence of jaundice the stools were acholic or hypocholic, the large, bulky, buttery stools said to result from the absence of the external secretion of the pancreas were not mentioned. Recent experimental work and clinical observations indicate that a large portion of the fats of ingested food can be utilized in the complete absence of pancreatic secretion (McClure, Vincent and Pratt, ${ }^{24}$ Whipple, et al.).

Nausea and Vomiting. Nausea, vomiting or both occurred with some frequency, being present in nearly one-half the cases. Various explanations have been given to account for the occurrence of these symptoms. Among them are stimulation of the branches of the vagus, exclusion of bile and pancreatic secretions from the intestine, neoplastic invasion of the gastrointestinal tract, or mechanical obstruction of the pylorus or duodenum from extrinsic pressure by neoplasm. In comparing this mixed group of cases with that of carcinoma of the body and tail of the pancreas, the incidence of nausea and vomiting was found to be considerably greater in the mixed group, composed as it was of a majority of jaundiced patients. In the previously reported group where biliary tract obstruction was absent, it was observed that nausea and vomiting were not frequent symptoms and when present were usually an accompaniment of paroxysms of pain and not important independent symptoms. Thus the suggestion that lack of bile and pancreatic juice are in part at least responsible seems plausible.

Of the thirty cases coming to necropsy (see below) neoplastic invasion of the gastrointestinal tract was noted in only eight cases and actual mechanical obstruction in only two. On the other hand, in the list of the eighty-nine operative cases, the findings were such in eight instances that in the judgment of the operator mechanical pyloric or duodenal obstruction sufficient to warrant posterior gastroenterostomy did exist. Similarly Rienhoff and Lewis reported that posterior gastroenterostomy was performed four times in 106 operations for carcinoma of the pancreas. Rives, Romano and Sandifer conclude that the explanation of nausea and vomiting probably lies in the direct involvement by neoplasm of the pancreas itself.

Duration of Symptoms. In Table $\mathrm{x}$ are shown the intervals of time, elapsing between the onset of symptoms and the 
time of admission to the hospital. The shortest period of illness recorded was two weeks and the longest three years. In view

TABLE $X$

DURATION OF SYMPTOMS

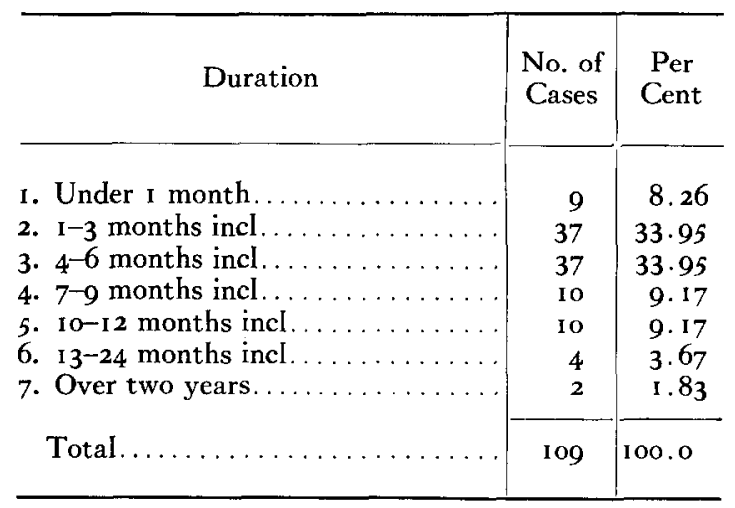

Shortest duration of symptoms-two weeks.

Longest duration of symptoms - three years.

Average duration of symptoms-five and five-tenths months.

of the notoriously rapid progress and relatively short life history of the disease, the histories of illness lasting over one year are perhaps open to some question. In such cases, it is quite possible that symptoms of antecedent chronic abdominal disease, such as chronic cholecystitis, cholelithiasis or peptic ulcer, may have merged with the earliest symptoms of the carcinoma.

It will be noted from the table that in 75 per cent of all of the cases the symptoms were of less than six months' duration, the average duration for the entire group being 5.5 months. It is interesting to compare this frgure with the average duration of symptoms of 5.7 months in the earlier report concerning carcinoma of the body and tail of the pancreas. Thus since these two figures are practically identical, the duration of symptoms in this larger group including many patients with jaundice was almost precisely the same as in the group of cancer of the body and tail of the pancreas only.

Since this average time interval between the beginning of symptoms and the time of hospital admission is much shorter than in the case of patients with many other types of carcinoma (of the breast or the rectum, for example) it might seem encouraging from the standpoint of treatment. As a matter of fact most of the cases were far advanced, as indicated by the necropsy group of thirty cases in which a lesion capable of being extirpated was found in only eight instances. The short duration of symptoms merely serves to emphasize the rapid progress of the disease.

Past History. Regarding previous diseases of the digestive tract which might have an etiologic bearing on the present trouble, the histories were relatively barren. Two patients gave a characteristic story of gall-bladder disease and four had had operations upon the biliary tract. Six patients gave a history of diabetes mellitus of long standing.

TABLE XI

POSITIVE FINDINGS NOTED ON PHYSICAL EXAMINATION IN IOG CASES

\begin{tabular}{|c|c|c|}
\hline Physical Signs & $\begin{array}{l}\text { No. of } \\
\text { Cases }\end{array}$ & $\begin{array}{c}\text { Per } \\
\text { Cent }\end{array}$ \\
\hline 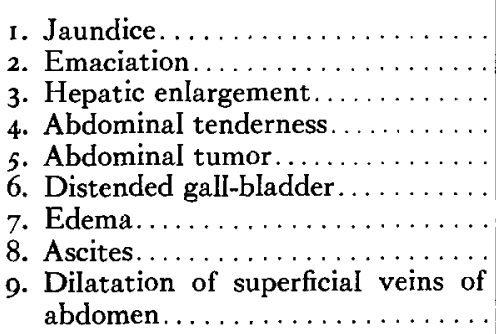 & $\begin{array}{l}84 \\
74 \\
65 \\
65 \\
42 \\
17 \\
17 \\
12 \\
8\end{array}$ & $\begin{array}{l}77.06 \\
67.89 \\
59.63 \\
59.63 \\
38.53 \\
15.60 \\
15.60 \\
11.01 \\
7.34\end{array}$ \\
\hline
\end{tabular}

Family History. The records of the family history as far as cancer was concerned were not very illuminating. Such histories, of course, are open to objection on the grounds of inaccuracy. In the present group of 109 cases, fourteen gave a history of cancer in the parents or grandparents or among siblings. The site of the lesion in these cases was so varied as to be of little interest and to have no practical bearing.

\section{PHYSICAL EXAMINATION}

In Table $\mathrm{xI}$ are shown in the order of frequency of their occurrence the positive findings noted on physical examination. 
Jaundice. This was the most common finding in the I09 cases, being present in 77 per cent. This observation is almost identical with those of Kiefer, Futcher, Leven, Friedenwald and Cullen, and Rives, Romano and Sandifer. Rienhoff and Lewis found jaundice in 69.22 per cent of their cases, while Mussey reported it in only 4 I per cent and Eusterman in 46 per cent. When present it is usually marked. 'This is attested to by the fact that eighty-three of the eighty-four jaundiced patients were aware of its existence and had mentioned it as one of their complaints.

Emaciation. Emaciation was recorded in seventy-four instances. In view of the history of considerable weight loss in the majority of cases, this number is probably unduly low. Undoubtedly emaciation of some degree was usually present, but was noted in the case record only when it was extreme.

Hepatic Enlargement. Enlargement of the liver was detected on clinical examination in 60 per cent of the cases. Obstructive jaundice is a well-known cause of hepatomegaly, as is also carcinoma of the liver. In the thirty cases coming to necropsy, hepatic metastases were found in thirteen.

Abdominal Tumor. An abdominal tumor mass other than the enlarged liver or the distended gall-bladder was noted in 39 per cent of the cases. A palpable tumor is found more frequently in the cases of cancer of the body or tail of the pancreas than in those of the head of the gland. In our series of cancers of the body and tail, a palpable tumor was present in 50 per cent of the cases. Abdominal tumors were described by Friedenwald and Cullen, Kiefer and Futcher in 43.25, and 27.27 and 57.14 per cent of their cases, respectively.

Distended Palpable Gall-Bladder. In accordance with Courvoisier's Iaw, a palpable, distended gall-bladder in the presence of jaundice should be pathognomonic of cancerous obstruction of the biliary tract. As shown in Table $\mathrm{xI}$ this finding did not prove to be of great assistance in arriving at a correct diagnosis, as the gall-bladder was palpable in only i 5.6 per cent of the series. It is true that this group includes fourteen cases of carcinoma of the body and one of the tail of the pancreas and three of the body and tail, in all of which jaundice was absent. Likewise, in the four cases each of carcinoma of the hepatic and of the cystic ducts, the usual mechanism of back pressure in the bile ducts and gallbladder would be lacking. Moreover, even though the gall-bladder is actually enlarged or distended, as subsequently revealed at operation or necropsy, it is frequently overlapped by the enlarged right lobe of the liver, so that the examiner fails to recognize it. In the thin patients, when a palpable gall-bladder was present, the enlarged viscus could usually also be observed on inspection of the abdomen, appearing as a globular swelling in the right upper quadrant. Rives, Romano and Sandifer report a somewhat similar experience in that the gall-bladder was palpated in only twenty-seven of their ninety-six cases prior to operation. On the other hand, Kiefer, Mussey, Eusterman, Kehr, ${ }^{25}$ Leven and Friedenwald and Cullen found palpable gall-bladders in from 50 per cent to 88 per cent of their cases.

Abdominal Tenderness. Abdominal tenderness was present in 60 per cent of the cases. It was rarely sharply localized and aided but little in the diagnosis. The incidence is essentially the same as that reported by other observers.

Edema, ascites and dilatation of the superficial veins of the abdomen were occasionally encountered. All were noted in patients with far advanced disease.

\section{LABORATORY EXAMINATIONS}

Urine. Urine analyses were recorded in all of the 109 cases under consideration. Dextrose was present in nine instances, in six of which there was a definite history of diabetes of fairly long duration, with blood sugar curves which confirmed the diagnosis. Glycosuria due to carcinoma of the pancreas per se appears to be an 
uncommon finding. Likewise the association between pancreatic carcinoma and diabetes mellitus seems to be purely coincidental, as six of the nine glycosuric patients were known diabetics. Thus, Kiefer points out that diabetes is quite frequent in the fifth and sixth decade of life and that in a similar number of persons of the same age as those having carcinoma of the pancreas, taken at random from the general population, there would be an appreciable number of diabetics. He also calls attention to the fact that liver damage resulting from biliary obstruction, infection, or involvement of the liver by metastatic carcinoma may alter carbohydratc mctabolism. Experimental work along these lines has been reported by Coller and Troost ${ }^{26}$ and clinical evidence by Conn and Newburgh. ${ }^{27}$

Bile was present in the urine of sixtyeight of the jaundiced cases, but unfortunately, in the remainder of these cases, the examination of the urine for bile was not reported.

The urine contained microscopic blood in sixteen cases, and in two there was gross hematuria. Bilirubinuria is often accompanied by albuminuria, due to renal irritation. The presence of microscopic blood may be explained on this basis in some cases.

Involvement of any portion of the urinary tract by neoplasm was a rare finding in the thirty cases examined postmortem. In only one was such involvement noted, and in this there was direct extension of a pancreatic cancer into the left kidney, adrenal and ureter.

Stools. Examination of the stool was reported in ninety-four of the cases. Claycolored stools were observed in fifty-two instances and gross blood was present in two. Occult blood, as demonstrated by the guaiac or benzidene tests, was found in thirty-four.

Gastric Analysis. Analysis of the stomach contents was made in fourteen cases. Hypoacidity or anacidity was present in ten cases, hyperacidity in one, while normal values were obtained in the remaining three.

Blood. Hemoglobin readings were recorded in 102 cases. The highest reading was I Io per cent and the lowest 24 per cent with an average determination of 74 per cent. (All of these determinations were made by the Sahli method.) Erythrocyte counts were made in seventyseven cases: the maximum number was $6,400,000$ and the minimum 2,000,000, with an average of $4,030,000$.

The leucocyte count was recorded in I 02 cases. The highest determination was 23,800 , an exceptional finding. The lowest determination was 2,100 , and the average 6,500 .

In this connection, it may be noted that the average temperature during the hospital stay or during the pre-operative period in the case of the patients operated upon, was under $100^{\circ} \mathrm{F}$. in ninety-six cases and over $100^{\circ} \mathrm{F}$. in only thirteen. Blood studies in general showed nothing characteristic which was of diagnostic value. It is interesting to note that in spite of the marked cancer cachexia so frequently noted, only a moderate degree of secondary anemia existed.

Blood Sugar. A determination of the fasting blood sugar was carried out in thirty-frve cases. Readings above $120 \mathrm{mg}$. per cent were noted in six cases, the highest reading being 290 . These six cases all gave a definite history of diabetes and the glucose tolerance test showed a typical diabetic curve. Of the remaining thirty cases, the highest fasting blood sugar determination was I Io $\mathrm{mg}$. per cent and the lowest 59, the average being 88. I.

Non-Protein Nitrogen. Determination of the blood non-protein nitrogen was made in twenty-frve cases, in only two of which were the readings over $40 \mathrm{mg}$. per cent, these being 48.2 and 75.9 respectively. Of the remainder, the lowest reading was 27.5 and the highest 40 , the average being 33.5 .

Blood Bilirubin. Blood bilirubin readings were made in only three of the non- 
jaundiced patients and in fifty-seven of the jaundiced patients. In the latter group the highest reading was $180 \mathrm{mg}$. per 1000 c.c. and the lowest 8 , with an average reading of 70.6 .

Wassermann and Kabn Reactions. The blood Wassermann or Kahn test for syphilis was recorded in ninety-three of the I09 cases, with the Wassermann reaction employed in the earlier cases and the Kahn test in the more recent ones. Of the thirteen Wassermann tests, the reaction was negative in ten, positive in two and questionable in one. Of the eighty reports on the Kahn reaction, there were seventynine which were negative and one positive. Thus in thesc nincty-thrce cases there wcre only three, or 3.2 per cent, which showed strongly positive tests. These findings tend to refute the statement that syphilis is an etiologic factor in carcinoma of the pancreas.

The remarkable thing about all of the laboratory studies was the fact that practically all of the findings were well within normal limits with the exception of the blood bilirubin determinations in the cases with jaundice. It is, in fact, surprising that more departures from the normal were not found in the various Iaboratory examinations. The only exception is, of course, in the cases with questionable jaundice in which an elevation of the bilirubin content of the blood may be of significance.

Roentgen Findings. Of considerably greater interest and value in diagnosis were the results of the roentgenologic examination. Such a study by means of the barium meal, with or without the examination of the colon by the barium enema, was made in ninety-three cases. Table XII gives the results of these studies. While the examination was entirely negative in three-fourths of the cases, it is significant that in the remaining one-fourth the findings were such that a pancreatic tumor was suspected or even a positive diagnosis ventured. The important positive findings were a widening of the normal duodenal curve, narrowing of the duodenal lumen or indentation of the shadow of the duodenum or stomach by pressure from without. In an indirect way, the examination was also of value in excluding carcinoma of the stomach or of the colon, both of which lesions may easily be confused with carcinoma of the pancreas, especially when jaundice is absent.

\begin{tabular}{|c|c|c|}
\hline $\begin{array}{c}\text { TABLE XII } \\
\text { ROFNTGFN FINDINCS IN } 93\end{array}$ & CASFS & \\
\hline Results of Examination & $\begin{array}{c}\text { No. of } \\
\text { Cases }\end{array}$ & $\begin{array}{l}\text { Per } \\
\text { Cent }\end{array}$ \\
\hline 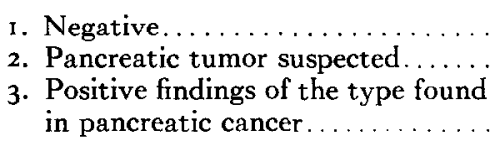 & $\begin{array}{l}69 \\
16 \\
8\end{array}$ & $\begin{array}{r}74.20 \\
\mathrm{I} 7.20 \\
8.60\end{array}$ \\
\hline $\begin{array}{r}\text { Total. } \ldots \ldots \ldots \ldots \ldots \ldots \\
\text { No examination } \ldots \ldots \ldots \ldots\end{array}$ & $\begin{array}{l}93 \\
16\end{array}$ & IOO.O \\
\hline Total. & 109 & \\
\hline
\end{tabular}

A matter of some scientific interest was the cholecystographic response. In the group of twenty-five non-icteric patients, cholecystography was employed nine times with the following results: non-visualization of the gall-bladder in five, normal visualization without stone in three and an unsatisfactory test in one. The examination was made in fifty-six of the eighty-four jaundiced cases. The results were: complete non-visualization of the gall-bladderforty-nine; faint visualization-two; normal visualization without stone-three; and an unsatisfactory examination in two.

\section{DIAGNOSIS}

In summarizing the foregoing remarks, it may be stated that in the presence of obstructive jaundice, the differential diagnosis of cancer of the head of the pancreas or bile ducts is frequently exceedingly difficult, cven with the assistance of all of the available laboratory data and roentgenologic studies.

When the classical Courvoisier-Terrier syndrome or the syndrome of Bard and $\mathrm{Pic}^{28}$ is present, little difficulty is encountered. These syndromes are characterized 
by progressive persistent and painless jaundice, dilatation of the gall-bladder, acholic stools, and associated cachexia. In the present study, such a clinical picture was unusual. On the contrary, pain was a prominent symptom, and being commonly situated in the upper abdomen or right upper quadrant, as well as tending to occur in attacks or paroxysms, it often simulated the picture of common duct stones or carcinoma of the gall-bladder. Even in carcinoma of the pancreas or bile ducts, definite remissions in the jaundice may occur, although it is rare for it to disappear completely at any time. The relatively short history and the marked cvidence of bodily detcrioration are perhaps the most important findings favoring a diagnosis of pancreatic cancer.

TABLE XIII

PRE-OPERATIVE DIAGNOSES IN PATIENTS WITH JAUNDICE

\begin{tabular}{|c|c|c|}
\hline Diagnosis & $\begin{array}{c}\text { No. of } \\
\text { Cases }\end{array}$ & $\begin{array}{l}\text { Per } \\
\text { Cent }\end{array}$ \\
\hline 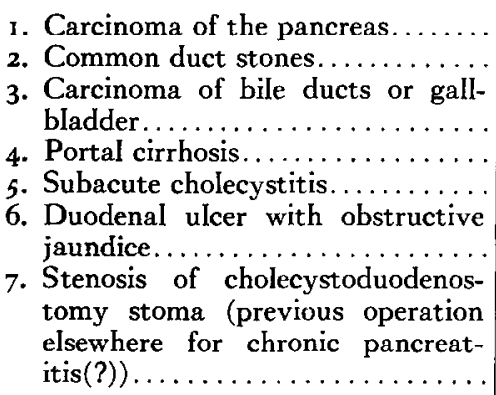 & $\begin{array}{l}7 \\
\text { I } \\
\text { I } \\
\text { I }\end{array}$ & $\begin{array}{r}66.66 \\
\text { I } 8.06 \\
9.72 \\
1.39 \\
1.39 \\
1.39\end{array}$ \\
\hline Total..... & 72 & 100.0 \\
\hline
\end{tabular}

Table xill presents the clinical diagnoses made prior to operation in the seventy-two jaundiced patients upon whom laparotomies were performed.

It will be noted that a correct diagnosis of cancer of the pancreas or bile ducts was made in over two-thirds of the cases and that the most frequent mistaken diagnosis was common duct stones. As a matter of fact, common duct stones coexisted with cancer in two instances. In onc, the primary lesion was in the head of the pancreas and was easily recognized at the time of operation, while in the other it was in the lower end of the common duct. In the latter case, the duct and gall-bladder contained white bile. In this case, the common duct carcinoma was not discovered until necropsy and microscopic examination of the tissues.

When jaundice is absent, the difficulties in diagnosis are greater and, as indicated in Table xIv, a correct pre-operative

TABLE XIV

PRE-OPERATIVE DIAGNOSES IN PATIENTS WITHOUT JAUNDICF

\begin{tabular}{|c|c|c|}
\hline Diagnosis & $\begin{array}{l}\text { No. of } \\
\text { Cases }\end{array}$ & $\begin{array}{l}\text { Per } \\
\text { Cent }\end{array}$ \\
\hline 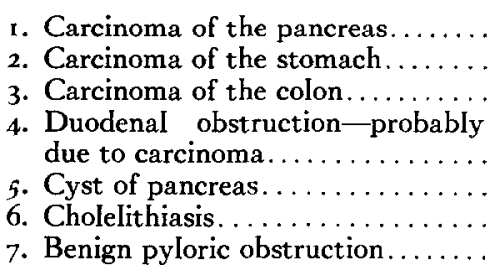 & $\begin{array}{l}7 \\
3 \\
2 \\
2 \\
\text { I } \\
\text { I } \\
\text { I }\end{array}$ & $\begin{array}{r}4 \text { I. } 19 \\
\text { I } 7.65 \\
\text { I } 1.76 \\
\\
\text { I . } .76 \\
5.88 \\
5.88 \\
5.88\end{array}$ \\
\hline Total. & I 7 & 100.0 \\
\hline
\end{tabular}

diagnosis of cancer of the pancreas was made in only $4 \mathrm{I}$ per cent of those cases. However, if the two cases in which a diagnosis of duodenal obstruction due to cancer was made are included, a reasonably correct diagnosis was made in slightly over 50 per cent of the cases. As shown in the table, cancer of the pancreas without jaundice, usually a carcinoma of the body or tail of the organ, was more often confused with carcinoma of the stomach or of the colon than with any other lesion. In these non-icteric patients, the main symptom was severe abdominal pain, often occurring in paroxysms or crises, and associated with rapid and extreme cmaciation. Roentgen studies of the gastrointestinal tract were at least suggestive in one-quarter of the cases. With the rapid advances being made in the freld of roentgenology, this method bids fair to be of much greater assistance in the future. 


\section{OPERATIVE FINDINGS}

Surgical operations were performed upon eighty-nine of the 109 cases under consideration. At the time of operation, jaundice was present in seventy-two or 80.9 per cent of this surgical group, while seventeen, or 19.I per cent, were free from jaundice. In the group of jaundiced patients, as shown in Table Xv, a distended gall-bladder

TABLE XV

CONDITION OF GALL-BLADDER AT TIME OF OPERATION (89 CASES)

\begin{tabular}{l|r|r}
\hline Condition of Gall-bladder & $\begin{array}{c}\text { No. of } \\
\text { Cases }\end{array}$ & $\begin{array}{c}\text { Per } \\
\text { Cent }\end{array}$ \\
\hline \multicolumn{2}{c}{ Patients with Jaundice (72 Cases) } \\
\hline
\end{tabular}

Patients without Jaundice (17 Cases)

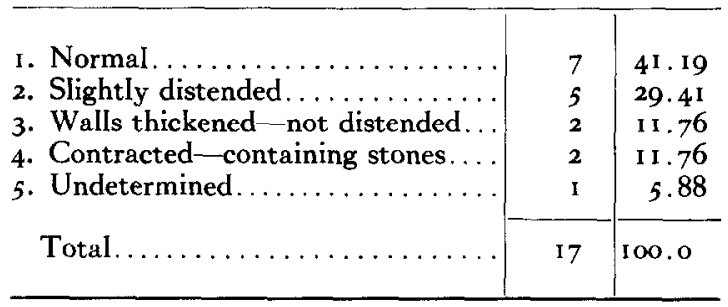

was found in sixty cases, or 83 per cent. In forty-eight of these, the gall-bladder wall appeared to be quite normal, while in twelve it was definitely thickened, apparently due to circulatory changes such as congestion and edema rather than fibrosis from chronic inflammation.

While in one case a cholecystoduodenostomy had previously been performed in an outside hospital, and in four of the cases the carcinoma was situated in the hepatic duct, the frgure 83 per cent seems to be a fair statement of the accuracy of Courvoisier's law.
In two of the cases of carcinoma of the hepatic duct, a collapsed and empty gallbladder was noted. Although a collapsed gall-bladder is rarely seen at the time of operation, it may be present under the above-mentioned circumstances. A tumor of the hepatic duct may prevent bile from entering the cystic duct and the usual mechanism responsible for the filling of the gall-bladder is thus interfered with.

In our experience, Courvoisier's law has proved to be of much greater value to the surgeon at the time of the laparotomy than to the clinician during the physical examination. Thus at the time of operation the presence of a distended gall-bladder, usually associated as it is with dilatation of the duct system, is indicative of an obstruction, probably neoplastic, at the lower end of the common duct and calls for a careful investigation of this region.

It will be noted that there was a rather marked discrepancy between the number of palpable gall-bladders detected prior to operation and the number found to be distended when the abdomen was opened. While this may be explained in part by lack of sufficient care on the part of the examiner, it is also true that a distended gall-bladder may escape notice in the case of a thick abdominal wall, especially when there is marked enlargement of the right lobe of the liver with overlapping of the gall-bladder.

Of considerable interest in both the icteric and non-icteric patients was the frequent finding of inflammatory lesions of the gall-bladder with or without stones. Thus, of the eighty-nine cases operated upon, there were eleven in which the gallbladder wall was thickened and in which distention was absent. In three of these cases stones were present. Further evidence on this score was obtained from biopsy specimens taken at the time of operation. When anastomoses between the gall-bladder and gastrointestinal tract were made, or when cholecystostomy was performed, a small bit of the gall-bladder was taken for microscopic examination on 
thirteen occasions. The histologic examination of the material showed invasion of the gall-bladder by carcinoma in two, and the remaining eleven showed chronic cholecystitis.

The nature of the gall-bladder contents is also of interest. In the entire group of eighty-nine surgical cases, stones were present in the gall-bladder in fifteen instances and in one an empyema of the gall-bladder was present as well. Thus in the present series there was a fairly high incidence of concomitant or antecedent infection of the biliary tract which may or may not have played a part in the subsequent development of the neoplasia.

As mentioned above, stones were encountered in the common duct on two occasions. In one, the carcinoma was of the ampulla and in one it was in the head of the pancreas. As a rule, carcinoma of the bile ducts is not associated with choledocholithiasis, and conversely in large groups of cases of common duct lithiasis, an associated duct carcinoma is a rare finding, quite unlike the usual association of stones with carcinoma of the gall-bladder.

However, one of the older views regarding the etiology of pancreatic cancer was that chronic irritation such as chronic pancreatitis was the precursor of the malignancy. Against this view is the fact that in the twelve cases of carcinoma of the pancreas coming to necropsy, only two showed histologic evidence of a chronic interstitial pancreatitis, the remainder of the pancreases showing no important abnormality other than the cancer.

Another point of interest was the fact that in twelve of the jaundiced cases, the gall-bladder contained "white bile" and in seven others, pale bile. Under such circumstances, excluding, of course, cases of hydrops due to stone in the cystic duct, the entire duct system usually contains the same type of material and denotes a marked depression of the liver function.

In these cases, it has been our custom, when possible, to perform an anastomosis between the gall-bladder and the gastro- intestinal tract, in the hopes that the release of back pressure and the free internal drainage of the biliary system will allow the liver to recover and regain its function. Occasionally this occurred and definite clinical improvement resulted from the operation. On the other hand, due to the impaired hepatic function, the danger of operation in these cases is great, as is indicated by the operative mortality of over 50 per cent for this particular group. The general impression that the presence of white bile in the gall-bladder and bile ducts in the presence of obstructive jaundice is of grave import was well borne out in the present study.

TABle XVI

CHARACTER OF GALL-BLADDER CONTENTS AT TIME OF OPERATION (89 CASES)

\begin{tabular}{c|c|c}
\hline Contents of Gall-bladder & $\begin{array}{c}\text { No. of } \\
\text { Cases }\end{array}$ & $\begin{array}{c}\text { Per } \\
\text { Cent }\end{array}$ \\
\hline
\end{tabular}

Patients with Jaundice (72 Cases)

\begin{tabular}{|c|c|c|}
\hline I. Thick concentrated bile. & 29 & 40.29 \\
\hline 2. Normal bile. & $\mathbf{1} 2$ & I6.67 \\
\hline 3. Pale bile. & 7 & $9 \cdot 72$ \\
\hline 4. White bile. & 7 & $9 \cdot 72$ \\
\hline 5. White bile and stones........ & 5 & 6.94 \\
\hline 6. Stones. . & 5 & 6.94 \\
\hline 7. Gall-bladder not opened...... & 4 & 5.55 \\
\hline 8. Normal bile with solitary stone.... & 2 & 2.78 \\
\hline 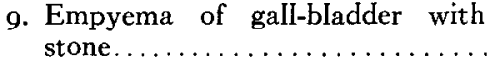 & $\mathbf{I}$ & I. 39 \\
\hline Total. & 72 & 100.0 \\
\hline
\end{tabular}

\begin{tabular}{|c|c|c|}
\hline \multicolumn{3}{|c|}{ Patients without Jaundice ( 7 Cases) } \\
\hline $\begin{array}{l}\text { 1. Gall-bladder not opened } \ldots \ldots \ldots \ldots \\
\text { 2. Normal bile } \ldots \ldots \ldots \ldots \ldots \ldots \ldots \ldots \\
\text { 3. Stones. } \ldots \ldots \ldots \ldots \ldots \ldots \ldots \ldots \ldots\end{array}$ & $\begin{array}{l}9 \\
6 \\
2\end{array}$ & $\begin{array}{l}52.94 \\
35.30 \\
\text { I } 1.76\end{array}$ \\
\hline Total. & 17 & 100.0 \\
\hline
\end{tabular}

Table XvII lists the various operations which were performed. Cholecystogastrostomy was the type of anastomosis which was most often feasible. While cholecystoduodenostomy was performed in seven cases without a death, it was employed only when an unusually mobile duodenum allowed the anastomosis to be performed 
without tension. Rienhoff and Lewis state that this type of operation should never be employed in carcinoma of the pancreas inasmuch as the duodenum is frequently involved or bound down by the growth. While theoretically the duodenum would be preferable to the stomach for the anastomosis, the functional results of the two operations were identical as far as could be determined. Lahey ${ }^{29}$ has recently advocated cholecystojejunostomy in preference to either cholecystogastrostomy or cholecystoduodenostomy. With this operation we have had no experience.

TABLE XVII

OPERATIONS PERFORMED AND OPERATIVE MORTALITY

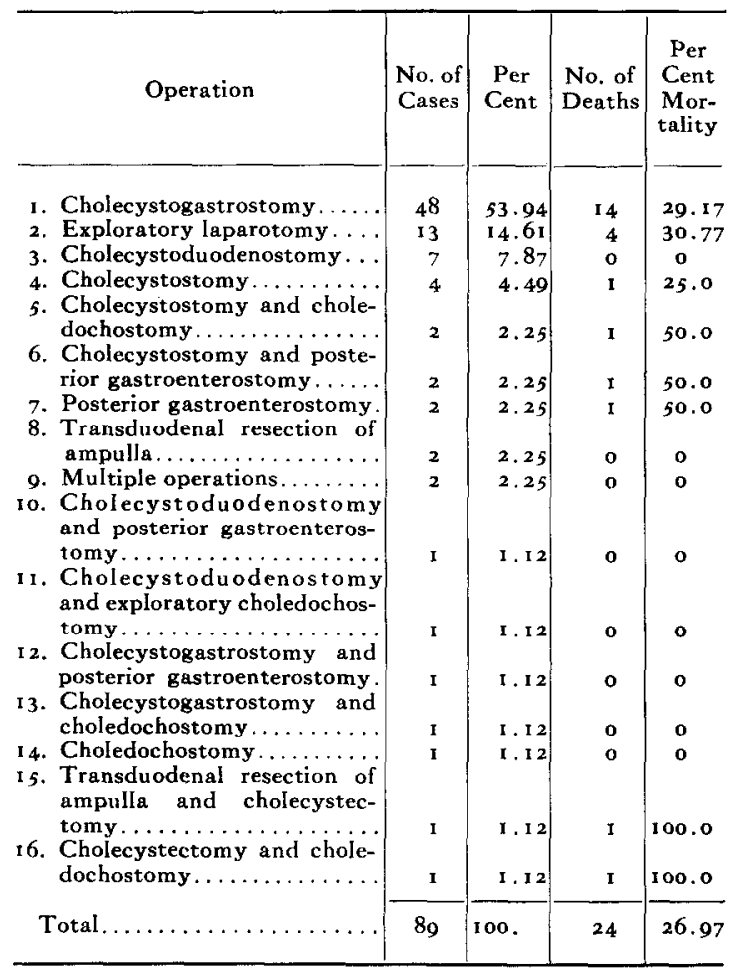

One of the patients who had multiple operations in the hospital had first a cholecystogastrostomy with subsequent disappearance of the jaundice. At a Iater date he developed symptoms of pyloric obstruction, necessitating a posterior gastroenterostomy. The second of these patients requiring multiple operations had had a cholecystoduodenostomy performed in another hospital for what was thought to be chronic indurative pancreatitis. He was admitted with recurrence of jaundice. Contraction of the stoma had occurred and accordingly the anastomosis was reestablished. He likewise subsequently developed pyloric obstruction and the next operation consisted of a posterior gastroenterostomy.

Aside from the three cases of resection of the lower end of the common duct for carcinoma of the ampulla of Vater, no radical resections were attempted. The majority of the patients had far advanced lesions and palliative procedures were the only ones which seemed justifiable. Table xvil also gives the hospital mortality for the various procedures. Obviously these mortality figures are of little importance in the selection of an operative procedure as many of the situations were desperate, and certain operations such as cholecystostomy or choledochostomy were frequently the only means of palliation possible. The total hospital mortality was 26.97 per cent.

In 1934, Coller and Winfreld ${ }^{30}$ reviewed the end-results of biliary intestinal anastomosis as a palliative operation in twentyone patients of this group, following their discharge from the hospital. The average duration of life was 7.2 months. In 78 per cent there was relief of pain, in 100 per cent relief of pruritus and partial or complete relief of jaundice in 95 per cent. Long periods of survival with complete relief of symptoms are occasionally reported. Two such cases have occurred in our experience. In such cases one is driven to the conclusion that the mass felt in the pancreas at the time of operation was in fact inflammatory rather than neoplastic, and that the internal drainage of the biliary tract resulted in a permanent cure. Unfortunately, the operative diagnosis of malignant disease is usually correct. Another argument in favor of exploration is the possibility that a common duct stone may be found. In such cases surgical removal can effect a cure and because of the possibility of a mistaken diagnosis, operation should not be withheld. 
Of the eighty-nine cases operated upon, biopsy material was taken at the time of the Iaparotomy in thirty-six, and in the three cases of resection for cancer of the ampulla, the entire lesion was removed. A microscopic diagnosis of cancer was made in the three latter cases. Of the thirty-six biopsy specimens, thirteen were taken from the gall-bladder, and as previously mentioned, eleven showed chronic cholecystitis and two invasion of the gall-bladder wall by carcinoma.

Biopsy of nodules in the liver was performed eight times and in each case the microscopic examination confirmed the operator's opinion of metastatic carcinoma. In three cases, nodules were removed from the omentum and all three showed carcinoma microscopically. In nine cases of advanced lesions of the common duct, a bit of tissue for biopsy was taken with the electrosurgical loop. The diagnosis of carcinoma was confirmed in all these instances by the pathologist. Lymph node biopsies were performed in six patients, a regional node being removed; in two of these, metastatic carcinoma was found and in the remaining four a chronic Iymphadenitis only. A biopsy specimen from a pancreatic lesion was taken four times. In three a diagnosis of carcinoma was reported and in one the examination was negative. Even with the electrosurgical loop, biopsy of the pancreas is decidedly hazardous, as troublesome bleeding may occur, which may be exceedingly difficult to control and may result in unnecessary prolongation of the operation. Furthermore, leakage of pancreatic secretions from one of the lesser pancreatic ducts may take place with disastrous results.

Table xvir shows in a comparative way the operative and the necropsy diagnosis in ten cases coming to post-mortem examination following surgery. The one patient with common duct stones had in addition a carcinoma of the lower end of the common duct which was not discovered until necropsy. Disregarding this one case, it will be noted that whereas the operator

made a diagnosis of pancreatic cancer in six cases and carcinoma of the bile ducts in three, this ratio was reversed when the necropsy findings were available. In other words, it seems quite impossible to distinguish either clinically or at the operating table between cancer of the common duct

\section{TABLE XVIII}

COMPARISON OF OPERATIVE AND NECROPSY DIAGNOSES IN IO POST-OPERATIVE DEATHS

Operative Diagnoses

I. Carcinoma of the pancreas..........

2. Carcinoma of bile

ducts.......... 3

3. Common duct stones 1

Total.

and of the head of the pancreas in many cases, and undoubtedly many cases recorded as pancreatic carcinoma were in reality examples of carcinoma of the bile ducts. Both lesions should therefore be included in any clinical discussion.

Table XIX

CAUSE OF DEATH IN 24 POST-OPERATIVE HOSPITAL DEATHS

\begin{tabular}{|c|c|c|c|}
\hline Cause & $\begin{array}{l}\text { No. of } \\
\text { Cases }\end{array}$ & $\begin{array}{l}\text { Au- } \\
\text { topsy }\end{array}$ & $\begin{array}{c}\text { No } \\
\text { Au- } \\
\text { topsy }\end{array}$ \\
\hline 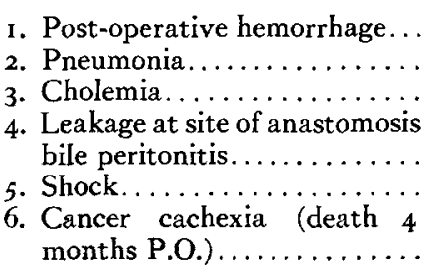 & $\begin{array}{l}\text { I } \\
2 \\
I\end{array}$ & $\begin{array}{l}5 \\
3 \\
0 \\
\text { I } \\
0\end{array}$ & $\begin{array}{l}3 \\
3 \\
6 \\
0 \\
2 \\
0\end{array}$ \\
\hline Total. . & 24 & Io & I4 \\
\hline
\end{tabular}

Table xix gives the cause of death in the twenty-four patients dying following surgical operation. Post-operative hemorrhage was responsible for death in one-third of the cases. A second common cause of death was pneumonia, not a surprising finding considering the fact that most of the patients were debilitated, cachectic and aged, poor surgical risks, especially for operations in the upper quadrants of the abdomen. Cholemia or hepatic insufficiency 
was likewise responsible for the fatal outcome in one-quarter of the cases, death usually occurring in about io to i4 days following operation. One death was due to bile peritonitis from a leaking suture line, while one patient remained in the hospital for four months after operation and ultimately succumbed to the disease.

\section{NECROPSY FINDINGS}

As noted in Table I, post-mortem examinations were conducted in thirty cases, ten of these being post-operative fatalities and the remaining twenty cases in which no operative treatment had been undertaken. During this same twelve year period a total number of 4,657 necropsies was performed. Thus in the necropsy material of the hospital there was an incidence of one case of carcinoma of the pancreas or bile ducts per I 55 necropsies.

TABLE XX

LOCATION OF PRIMARY LESION IN 30 NECROPSIES

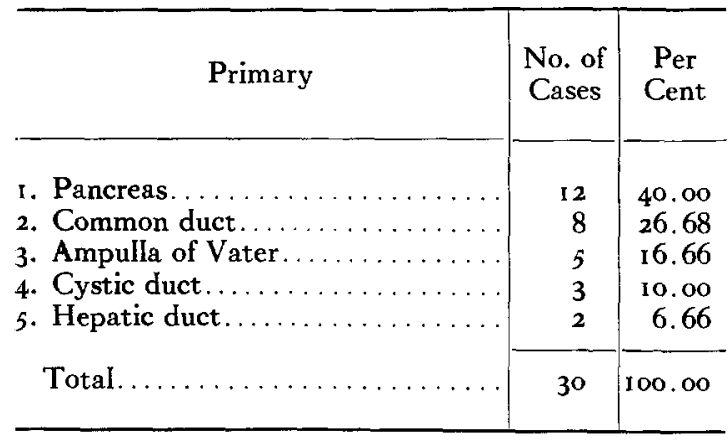

Table $\mathrm{xx}$ shows the location of the primary lesion in these thirty cases as it was determined by the histologic examination of the necropsy material. While this group of cases is admittedly small, it is of considerable interest to note that primary carcinoma of the extrahepatic bile ducts occurred one and one-half times as frequently as primary carcinoma of the pancreas. As mentioned above, it is probably true that many cases in which a clinical or even an operative diagnosis of carcinoma of the head of the pancreas is made, are in reality cases of primary carcinoma of the bile ducts. While such a distinction is often of academic interest only, it nevertheless indicates the possibility of complete extirpation of the lesion if a timely operation is performed. Assuming that the incidence of carcinoma of the Iower common duct or ampulla is somewhat greater than has been generally realized, it is probable that in the future more cases will be found suitable for radical surgery than has been the case heretofore. With the two-stage procedure of Whipple, Parsons and Mullins, the hazard of operation is considerably reduced, whilc a sufficiently wide margin of tissue is resected to make permanent cure possible.

According to the post-mortem findings, five of the duct carcinomas were quite localized, without distant metastases, and complete eradication of the lesion would have been possible. The same was true of only two of the pancreatic cancers, one of which was situated in the head of the organ and the other in the body.

Table xxI indicates the location of metastatic lesions in the nineteen cases

TABLE XXI

METASTASES AS FOUND AT NECROPSY IN 19 CASES Metastases

No, of Cases

I. Regional Iymph nodes. . . . . . . . . . 3

2. Liver and lungs $\ldots \ldots \ldots \ldots \ldots \ldots \ldots \ldots \ldots$

3. Liver and retroperitoneal lymph nodes....... 2

4. Liver. . . . . . . . . . . . . . . . . I

5. Bone marrow . . . . . . . . . . . . . . . I

6. Liver-regional lymph nodes and lungs........ I

7. Mesenteric lymph nodes............... I

8. Liver-lungs. Peripancreatic lymph nodes, retroperitoneal Iymph nodes, bronchial nodes and thyroid.

9. Liver, adrenal, retroperitoneal lymph nodes, sternum, thoracic and lumbar vertebrae, and right pectoral muscle.

Io. Liver-portal and peripancreatic lymph nodes, tail of pancreas, capsule of spleen, lungs and bronchial lymph nodes. .

I 1. Liver, peritoneal surfaces, omentum, mesentery and regional lymph nodes. ............. I

1 2. Left thoracic wall, ribs, sternum, vertebrae, retroperitoneal nodes, liver, spleen, adrenal, lung, mediastinal and axillary Iymph nodes... I I

13. Duodenum, peripancreatic lymph nodes, pericholedochotic tissues, liver and gall-bladder.... I

14. Regional, mesenteric, mediastinal and peribronchial nodes, under-surface of diaphragm, liver, gall-bladder, lungs, pleura, sternum and sixth right rib.................. I

15. Regional lymph nodes, lungs, bronchial and mediastinal nodes, diaphragm, small intestine and appendix $\ldots \ldots \ldots \ldots \ldots \ldots \ldots \ldots$ 
in which metastases were found. The regional lymph nodes were involved in fifteen cases, while hepatic metastases occurred in thirteen and pulmonary metastases in eight.

TABLE XXII

DIRECT EXTENSION OF NEOPLASM AS FOUND AT NECROPSY IN I 5 CASES

Primary Carcinoma of Bile Ducts

Extension

No. of Cases

I. Head of pancreas $\ldots \ldots \ldots \ldots \ldots \ldots \ldots \ldots \ldots$

2. Duodenum.................... 2

3. Liver. ...................... I

4. Pancreas and omentum ............. I

5. Gall-bladder and Iiver................. I

6. Head of pancreas and duodenum .......... I

7. Hepatogastric ligament and liver.......... I

Primary Carcinoma of Pancreas

Extension

No. of Cases

I. Duodenum....................

2. Common duct.................... I

3. Peripancreatic and retroperitoneal tissues, left adrenal, kidney and ureter

4. Liver, gall-bladder, duodenum, small intestine and colon .................... I

Table xxir shows the various regions involved by direct extension of the neoplastic process. In the case of primary carcinoma of the bile ducts, the pancreas was often infiltrated, thus accounting for the ease and frequency with which a diagnosis of primary carcinoma of the pancreas was made at the operating table.

In four cases in the necropsy group multiple malignancies were present, there being a second independent primary carcinoma in addition to that found in the pancreas or bile ducts (Table xxIII).

\section{TABLE XXIII}

CASES OF MULTIPLE MALIGNANCIES IN 30 NECROPSIES I. C. R. Path No. A-43-A. K. -male 63 .

(a) Undifferentiated medullary adenocarcinoma of pancreas.

(b) Recurrent medullary squamous cell carcinoma of the lip.

2. J. P. Path No. A-26o-A. L.-female 48.

(a) Medullary adenocarcinoma of pancreas.

(b) Early carcinoma arising in right multilocular parovarian cystadenoma.

3. P. L. Path No. A-220-A. J.-male 63.

(a) Advanced adenocarcinoma of common duct at ampulla of Vater.

(b) Early medullary carcinoma of prostate.

4. H. R. Path No. A-64-A. M.-male 54.

(a) Gland cell carcinoma of head of pancreas.

(b) Primary medullary squamous cell carcinoma of upper and middle Iobes of right lung.

While various factors such as alcohol, syphilis and chronic inflammation have been suggested as etiologic agents in pancreatic cancer, there is little positive evidence to support these views. In this necropsy group of thirty cases, there was histologic evidence of syphilis in only six and these were all cases of cancer of the bile ducts rather than of the pancreas.

\section{SUMMARY}

I. A group of 109 cases of carcinoma of the pancreas and extrahepatic bile ducts, verifred by operation or necropsy, has been reviewed.

2. The disease occurred approximately twice as frequently in males as in females.

3. The average age of the patients was 56.9 years.

4. Weight loss was the most common symptom. It was usually extreme (average I3.8 kg.) and occurred rapidly.

5. Jaundice was the most common chief complaint and abdominal pain the most common initial symptom.

6 . The average duration of symptoms was 5.5 months.

7. Jaundice was the most common physical sign and was present in over threefourths of the cases.

8. Courvoisier's law was of relatively little value in making a correct diagnosis prior to operation. The law was of considerable value to the surgeon at the time of laparotomy, as it indicated the type of duct obstruction which was present. The operative findings proved the law to be accurate in over 80 per cent of the cases.

9. Laboratory studies were of practically no value in diagnosis.

10. Roentgen studies were positive or suggestive in one-fourth of the cases.

I I. In the non-icteric patients the difflculties in diagnosis were greater than in the icteric group. In the former cases the condition was most often confused with carcinoma of the stomach or colon.

I2. Evidence of antecedent biliary tract infection, as indicated by contraction of the gall-bladder or thickening of its waIl, was noted in approximately one-eighth of the operative cases, while calculi were present in the gall-bladder in one-sixth. 
13. Cholecystogastrostomy was regarded as the best palliative operation. The operative mortality for this procedure was 29. I 7 per cent.

14. In ten cases, according to the diagnoses made at the time of operation, the ratio of cases of carcinoma of the pancreas and of the bile ducts was 2: I. Necropsy examination of these same cases proved that the ratio was $\mathrm{I}: 2$.

15. In three cases of carcinoma of the ampulla of Vater, transduodenal resection was performed, with one post-operative death and two recoveries.

I6. Hemorrhage was the most common cause of death following operation.

17. The average duration of life following palliative biliary gastrointestinal anastomosis was 7.2 months in a group of twenty-one patients traced.

I8. Post-mortem examination showed the most common site of metastases to be the regional lymphnodes, while metastases to the liver and lungs occurred next in frequency.

19. In the group of thirty cases examined post-mortem, there were four instances of multiple malignancies.

\section{REFERENCES}

I. Courvoisier, L. G. Casuistisch-statistisch Beiträge zur Pathologie und Chirurgie der Gellenwege. Leipsig, I89o. Vogel. p. 58 .

2. Graham, Evarts A. Diseases of the liver and biliary passages. Surgical Diagnosis, 3: 47 I, 1930. W. B. Saunders Co.

3. Cronn, B. B. New growths involving the terminal bile and pancreatic ducts: their early recognition by means of duodenal-content analyses. $A m$. $J$. M. Sc., I 48: 839-856, 19г4.

4. Potter, E. B. Successful resection of the common bile ducts for carcinoma of the ampulla of Vater. Ann. Surg., 98: 369-373 (Sept.) I933.

5. Judd, E. S., and PArker, B. R. Biliary intestinal anastomosis for obstructive jaundice: analysis of 137 consecutive cases. Arcb. Surg., 17: I-17 (JuIy) 1928 .

6. Walters, Waltman. Successful resection of the ampulla of Vater, including a portion of the duodenum with choledochoduodenostomy for carcinoma of the ampulla of Vater. Surg., Gynec. es Obst., 55:648-65 I (Nov.) 1932.

7. Hunt, V. C., and Budd. J. W. TransduodenaI resection of the ampulla of Vater for carcinoma of the distal end of the common duct. Surg., Gynec. of Obst., 61: 651-66r (Ngv.) 1935.
8. Whipple, Allen O., Parsons, William Barclay, and Mullins, Clinton R. Treatment of carcinoma of the ampulla of Vater. Ann. Surg., Ioz: 763-779 (Oct.) I935.

9. Clute, H. M. The problem of cancer of the pancreas. J. A. M. A., 107: 91-97, 1936.

to. Rives, James D., Romano, Samuel A., and SANDifer, Fred M. JR. Carcinoma of the pancreas. Surg., Gynec. obst., 65: 164-177 (Aug.) 1937.

i . Mrrallie, C. Cancer primitif du pancréas, Gaz.d. bôp., 46: 889 (Aug. 19), 1893.

I2. DaCosta, J. M. Cancer of the pancreas, Nortb America Med.-Cbir. Rev., 2: 883, 1858; Fr. Patb. Soc., 1: 8 and 709, I860.

13. Speed, Kellogg. Carcinoma of the pancreas. Am. J. M. Sc., I6o: I (July) ig2o.

14. Futcher, T. B. Cancer of the pancreas. $T r$. A. A. Pbysicians, 34: 284, I919.

15. Ancelot, E. Maladies du pancréas. Paris, 1864. F. Savy, p. 53 .

i6. Leven, N. L. Primary carcinoma of the pancreas Am. J. Cancer, 18: 852-874 (Aug.) 1933.

17. Friedenwald, Julius, and Cullen, T. S. Carcinoma of the pancreas: clinical observations. Am. J. M. Sc., 176: 31 (July) 1928.

i8. Rienhoff, Wm. F., JR., and Lewis, Dean L. Surgical affections of the pancreas. Bull. Jobns Hopkins Hosp., 54: 386-429 (June) I934.

19. Kiefer, E. S. Carcinoma of the pancreas. Arcb. Int. Med., 40: I (JuIy) I927.

20. Hick, F. K., and Mortimer, H. M. Carcinoma of the pancreas. J. Lab. \& Clin. Med., 19: $1058-1067$ (July) I934.

21. Eusterman, G. B. Carcinoma of the pancreas: a clinical study of 138 cases. Coll. Papers Mayo Clinic, 14: 206-215, 1922.

22. Mussey, R. D. Pancreatic carcinoma. Med. Clin. Nortb America, 3: 681-688, I919.

23. Ransom, Henry K. Carcinoma of the body and tail of the pancreas. Arcb. Surg., 30: $584-606$ (April) 1935 .

24. McClure, C. W., Vincent, B., and Pratt, J. H. The absorption of fat in partially and completely depancreatized dogs. J. Exper. Med., 25: $381,1917$.

25. Kenr, H. Über Erkrankungen des Pankreas under besonderer Beruckrichtigung der bei der Cholelithiasis borkommenden Pankreatitis. Mitt. a.d. Greuzget. d. Med. u. Cbir., 20: 45-149, 1909.

26. Coller, Frederick A., and Troost, F. L. Glucose tolerance and hepatic damage. Ann. Surg., 90: $781-793$ (Oct.) ig29.

27. Conn, J. W., and Newburgh, L. H. Hyperglycemia due to impaired hepatic glycogenesis. Proc. Soc. Exper. Biol. er Med., 36: 236-238 (Mar.) 1937.

28. BARD, L., and PIC, A. Contribution à l'étude clinique et anatomopathologique du cancer primitif du pancréas. Rev. de méd., 8: 257-282, I 888.

29. Lahey, Frank H. Carcinoma of the pancreas. Surg. Clin. Nortb America, 17: 753-762 (June) I937.

3o. Coller, Frederick A., and Winfield, James M. Evaluation of palliative operation for cancer of the pancreas. Am. J. Surg., 25: 64-69 (July) 1934 . 